\title{
Pilihan Terbaik Sidebar Kanan atau Kiri untuk Personal Website berdasarkan Usability
}

\author{
Edi Susilo $^{1}$, Salhazan Nasution ${ }^{2}$, dan Rahmat Rizal Andhi ${ }^{3}$ \\ Program Studi Teknik Informatika, Fakultas Teknik, Universitas Riau \\ edi.susilo@lecturer.unri.ac.id ${ }^{1}$, salhazan@lecturer.unri.ac.id ${ }^{2}$, rahmat.rizal@secturer.unri.ac.id ${ }^{3}$
}

\begin{tabular}{l}
\hline \hline Article Info \\
\hline History : \\
Dikirim 26 Desember 2019 \\
Direvisi 19 Januari 2020 \\
Diterima 28 Februari 2020 \\
\hline
\end{tabular}

Kata Kunci:

Sidebar Kanan

Sidebar Kiri

Website

Usability

\begin{abstract}
Abstrak
Penelitian ini melakukan pengujian usability pada personal website. Pengujian fokus pada pemilihan terbaik antara penerapan sidebar kanan atau kiri. Pengujian usability menggunaan System Usability Scale (SUS). Pengambilan datanya menggunakan kuesioner yang diberikan ke responden berjumlah 16 pengguna. Responden terdiri dari 8 pengguna yang memiliki dominan tangan kanan dan 8 pengguna yang memiliki dominan tangan kiri. Hasil pengujian usability pada sidebar kanan mendapatkan skor 80 dan sidebar kiri mendapatkan skor 59. Dari hasil pengujian usability, sidebar kanan mendapatkan skor yang lebih tinggi. Selain pengambilan data menggunakan SUS, dilakukan juga wawancara kepada semua responden. Hasilnya pengguna lebih menyukai sidebar berada di sebelah kanan.
\end{abstract}

(C) This work is licensed under a Creative Commons Attribution-ShareAlike 4.0 International License.

\author{
Koresponden: \\ Edi Susilo \\ Program Studi Teknik Informatika, Fakultas Teknik \\ Universitas Riau \\ J1. HR Subrantas km 12,5 Pekanbaru, Riau \\ Email : edi.susilo@lecturer.unri.ac.id
}

\section{PENDAHULUAN}

Website menjadi media informasi yang mudah diakses. Website dapat diakses melalui perangkat desktop, tablet maupun mobile hanya dengan menggunakan aplikasi browser. Selain sebagai media penyebaran informasi, fungsi website juga dapat digunakan untuk personal branding.

Personal branding merupakan proses terencana untuk melakukan upaya memasarkan diri [1]. Personal branding dapat menggunakan website sebagai salah satu alatnya. Agar personal branding melalui website maksimal, user interface (UI) website perlu dimaksimalkan karena memiliki peran penting dan sekaligus menjadi penghubung secara langsung antara sistem dengan penggunanya [2].

Ada 3 prinsip dalam mendesain sebuah website menurut Veen's design principles [3], yaitu bisa menjawab pertanyaan (1) Di mana saya?, (2) Kemana saya bisa pergi?, dan (3) Ada apa di sini? Pertanyaan (1) menggambarkan website harus memiliki header yang menjelaskan website apa, pertanyaan (2) menggambarkan adanya navigasi yang pada gambar 1 diposisikan di sidebar dan yang ke (3) adalah konten dari website. Letak dari 3 pertanyaan Veen's design principles pada desain website seperti pada Gambar 1.

Pada pertanyaan (2) tidak dijelaskan pada Veen's design principles [3] posisi yang terbaik peletakan navigasinya. Sedangkan navigasi pada website bisa diletakkan di posisi sebelah kanan konten (sidebar kanan) 


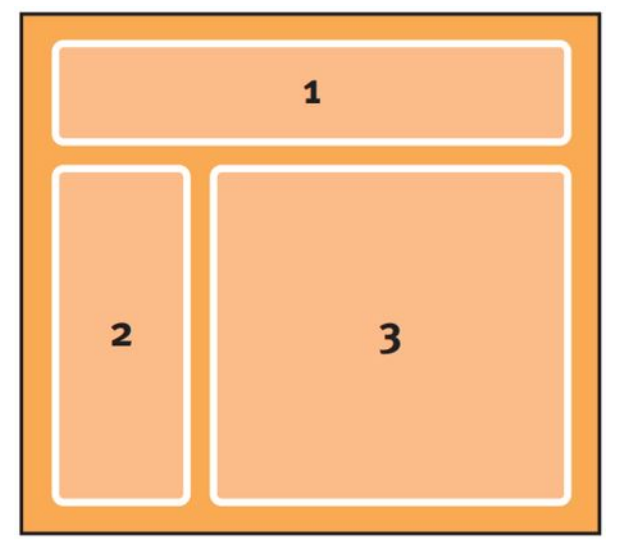

Gambar 1. Desain website Veen's design principles [3].

atau diletakkan di sebelah kiri konten (sidebar kiri). Selain itu, belum ditemukan penelitian yang mengkaji masalah ini. Untuk memaksimalkan desain personal website, maka perlu dilakukan penelitian untuk memilih yang terbaik antara sidebar kanan atau kiri.

Penentuan yang terbaik antara sidebar kanan atau kiri perlu memperhatikan aspek dalam perancangan UI. Salah satu yang perlu memperhatikan dalam perancangan UI website adalah aspek usability [4]. Usability merupakan atribut kualitas yang membantu menentukan efisiensi, tingkat efektivitas dan kepuasan pengguna pada saat interaksi dengan sistem [5].

Mengetahui tingkat kualitas usability umumnya dilakukan menggunakan kuesioner. Ada banyak jenis kuesioner yang digunakan pada pengujian usability untuk website, seperti: SUS (System Usability Scale), QUIS (Questionnaire for User Interface Satisfaction), CSUQ (Computer System Usability Questionnaire), dan Words (adapted from Microsoft's Product Reaction Cards) [6]. Dari beberapa alat pengujian usability tersebut, SUS merupakan kuesioner yang paling dapat diandalkan dan juga sederhana untuk mengujian usability pada website [6].

Penelitian [5] melakukan evaluasi pada UI website menggunakan usability. Usability yang diukur adalah tingkat efisiensi, efektivitas dan kepuasan pengguna menggunakan tugas khusus. Responden hanya berjumlah 5 pengguna, yang terdiri dari 2 laki-laki dan 3 perempuan. Tidak ada kriteria khusus dalam pemilihhan responden. Sedangkan pada penelitian ini untuk mendapatkan yang terbaik antara sidebar kanan atau kiri perlu adanya kriteria khusus.

Setiap pengguna memiliki dominasi tangan yang berbeda saat menggunakan sesuatu. Ada penguna yang dominan tangan kanan dan ada yang dominan tangan kiri. Untuk mendapatkan yang terbaik, mana pengujian mana yang terbaik antara sidebar kanan atau kiri perlu memperhatikan dominasi tangan kanan dan tangan kiri pengguna.

Pada penelitian ini, dilakukan pengujian usability pada personal website menggunakan SUS. Pengujian usability dengan membagikan kuesioner ke responden. Responden terbagi menjadi 2, yaitu responden yang dominan tangan kanan dan responden yang dominan tangan kiri. Hasilnya diharapkan mendapatkan pilihan yang tepat antara sidebar kanan atau kiri untuk personal website.

\section{METODE PENELITIAN}

Alat yang digunakan untuk pengujian usability pada penelitian ini adalah System Usability Scale (SUS). SUS dipilih karena kuesioner yang sederhana dan paling dapat diandalkan untuk pengujian usability pada website [6]. SUS memiliki 10 pertanyaan dan 5 pilihan jawaban mulai dari sangat tidak setuju sampai dengan sangat setuju [7]. Skor SUS minimal adalah 0 dan skor maksimal adalah 100. Pertanyaan SUS menggunakan versi Indonesia yang sudah diterjemahkan dari versi original berbahasa inggris pada penelitian [8] seperti pada Tabel 1.

Kuesioner SUS dibagikan kepada responden berjumlah 16 pengguna. Penentuan jumlah responden berdasarkan pada penelitian [6], menyatakan bahwa dibutuhkan ukuran sampel minimal 12-14 peserta untuk 
Tabel 1. Item pertanyaan SUS Versi Indonesia [8].

\begin{tabular}{ll}
\hline No. & \\
\hline 1 & Saya berpikit akan menggunakan system ini lagi \\
\hline 2 & Saya merasa sistem ini rumit untuk digunakan \\
\hline 3 & Saya merasa sistem ini mudah untuk digunakan \\
\hline 4 & Saya membutuhkan bantuan dari orang lain atau teknisi dalam menggunakan sistem ini \\
\hline 5 & Saya merasa fitur-fitur sistem ini berjalan dengan semestinya \\
\hline 6 & Saya merasa ada banyak hal yang tidak konsisten (tidak serasi) pada sistem ini \\
\hline 7 & Saya merasa orang lain akan memahami cara menggunakan sistem ini dengan cepat \\
\hline 8 & Saya merasa sistem ini membingungkan \\
\hline 9 & Saya merasa tidak ada hambatan dalam menggunakan sistem ini \\
\hline 10 & Saya perlu membiasakan diri terlebih dahulu sebelum menggunakan sistem ini \\
\hline
\end{tabular}

hasil yang cukup andal. Pengguna terdiri dari 8 pengguna yang memiliki dominan tangan kanan dan 8 pengguna yang memiliki dominan tangan kiri. Rekrutmen responden dilakukan berdasarkan volunteer basis yang ada dilingkungan jurusan Teknik Elektro, Fakultas Teknik, Universitas Riau.

Pengambilan data dilakukan 2 kali pada setiap responden. Pertama, reponden akan menggunakan personal website yang memiliki sidebar kanan seperti pada Gambar 2. Kemudian dilanjutkan dengan pengisian kuesioner SUS yang pertama.

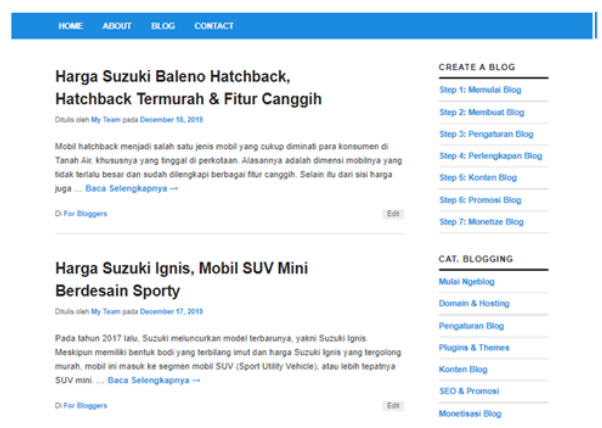

Gambar 2. Website dengan sidebar kanan

Kedua, responden akan menggunakan personal website yang memiliki sidebar kiri seperti pada Gambar 3. Dilanjutkan dengan pengisian kuesioner SUS yang kedua. Kemudian akan didapatkan data yang akan dianalisis sesuai pergitungan SUS.

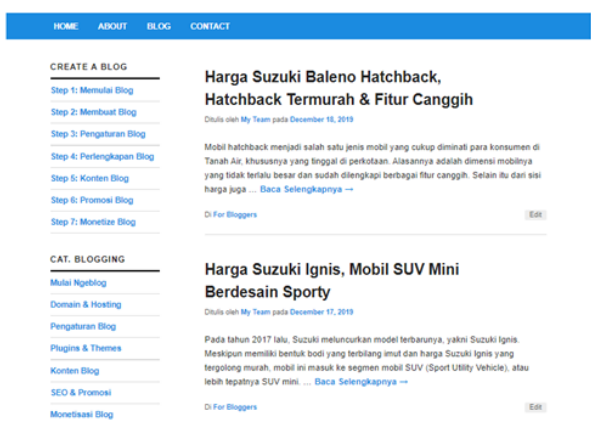

Gambar 3. Website dengan sidebar kanan

Selain melakukan pengambilan data menggunakan kuesioner SUS, pengambilan data juga melakukan dengan wawancara. Wawancara dilakukan kepada semua responden. Tujuan wawancara untuk mendapatkan 
masukan dari responden mana yang terbaik dari sidebar kanan atau kiri dan apa alasannya.

\section{HASIL DAN PEMBAHASAN}

Hasil dari pengambilan data menggunakan kuesioner SUS, kemudian dilakukan perhitungan sesuai dengan prosedur SUS. Hasil pengujian usability menggunakan SUS pada personal website dengan sidebar kanan ditunjukkan pada Tabel 2.

Tabel 2. Hasil Perhitungan SUS pada Sidebar Kanan

\begin{tabular}{cccc}
\hline Responden & Tangan Dominan & Pekerjaan & Skor SUS \\
\hline R1 & Tangan Kanan & Mahasiswa & 63 \\
\hline R2 & Tangan Kanan & Mahasiswa & 90 \\
\hline R3 & Tangan Kanan & Mahasiswa & 88 \\
\hline R4 & Tangan Kanan & Mahasiswa & 88 \\
\hline R5 & Tangan Kanan & Mahasiswa & 88 \\
\hline R6 & Tangan Kanan & Mahasiswa & 78 \\
\hline R7 & Tangan Kanan & Mahasiswa & 75 \\
\hline R8 & Tangan Kanan & Mahasiswa & 58 \\
\hline R9 & Tangan Kiri & Mahasiswa & 93 \\
\hline R10 & Tangan Kiri & Mahasiswa & 78 \\
\hline R11 & Tangan Kiri & Mahasiswa & 63 \\
\hline R12 & Tangan Kiri & Mahasiswa & 88 \\
\hline R13 & Tangan Kiri & Mahasiswa & 80 \\
\hline R14 & Tangan Kiri & Mahasiswa & 88 \\
\hline R15 & Tangan Kiri & Mahasiswa & 80 \\
\hline R16 & Tangan Kiri & Mahasiswa & 83 \\
\hline \multicolumn{5}{c}{ Skor rata-rata } & 80 \\
\hline
\end{tabular}

Dari hasil perhitungan SUS pada pengujian personal website dengan sidebar kanan, didapatkan skor rata-rata 80. Skor ini di atas rata-rata dari banyaknya penelitian menggunakan SUS, yaitu 68 [9]. Kemudian hasil pengujian usability menggunakan SUS pada personal website dengan sidebar kiri ditunjukkan pada Tabel 3.

Hasil perhitugan SUS pada personal website dengan sidebar kiri mendapatkan skor rata-rata 59. Skor ini dibawah rata-rata dari banyaknya penelitian, yaitu 68 [9]. Kemudian skor SUS dibandingkan dengan merujuk pada Gambar 4.

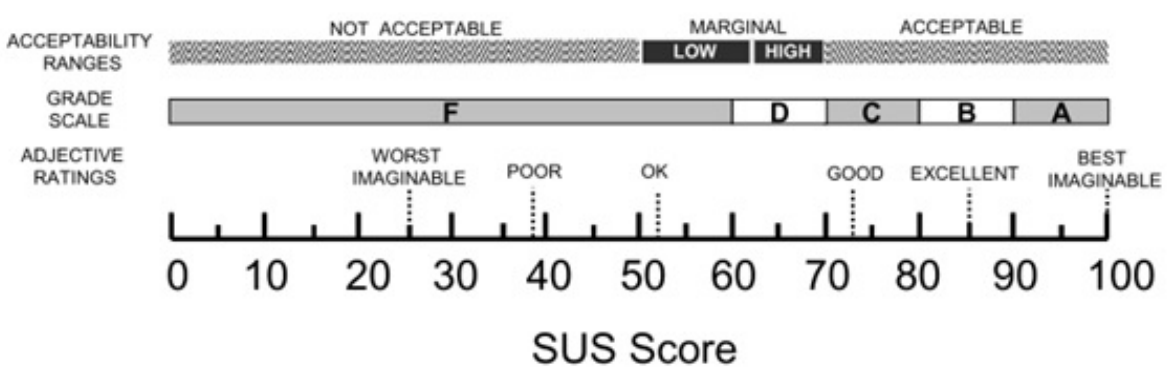

Gambar 4. Dasar penilaian skor SUS

Skor SUS pada personal website dengan sidebar kanan masuk dalam peringkat "EXCELLENT" dam personal website dengan sidebar kiri masuk dalam peringkat "GOOD". Jika dilihat dari skor keduanya antara sidebar kanan 80 dan sidebar kiri 59, sidebar kanan mendapatkan skor lebih tinggi dari sidebar kiri. Secara 
Tabel 3. Hasil Perhitungan SUS pada Sidebar Kiri

\begin{tabular}{ccc}
\hline Responden & Tangan Dominan & Skor SUS \\
\hline R1 & Tangan Kanan & 88 \\
\hline R2 & Tangan Kanan & 50 \\
\hline R3 & Tangan Kanan & 33 \\
\hline R4 & Tangan Kanan & 75 \\
\hline R5 & Tangan Kanan & 60 \\
\hline R6 & Tangan Kanan & 35 \\
\hline R7 & Tangan Kanan & 40 \\
\hline R8 & Tangan Kanan & 65 \\
\hline R9 & Tangan Kiri & 35 \\
\hline R10 & Tangan Kiri & 50 \\
\hline R11 & Tangan Kiri & 45 \\
\hline R12 & Tangan Kiri & 90 \\
\hline R13 & Tangan Kiri & 53 \\
\hline R14 & Tangan Kiri & 75 \\
\hline R15 & Tangan Kiri & 73 \\
\hline R16 & Tangan Kiri & 78 \\
\hline \multicolumn{2}{c}{ Skor rata-rata } & 59
\end{tabular}

sederhana dapat disimpulkan bahwasannya sidebar kanan merupakan pilihan terbaik untuk diterapkan pada personal website.

Selain pengambilan data menggunakan SUS, dilakukan juga wawancara kepada semua responden. Wawancara ini dilakukan untuk mendapatkan masukan dari responden mana yang terbaik dari sidebar kanan atau kiri. Hasil wawancara mengenai pilihan posisi sidebar pada personal website ditunjukkan pada Tabel 4.

Tabel 4. Hasil Wawancara

\begin{tabular}{ccc}
\hline Responden & Tangan Dominan & Pilihan Sidebar \\
\hline R1 & Tangan Kanan & Kiri \\
\hline R2 & Tangan Kanan & Kanan \\
\hline R3 & Tangan Kanan & Kanan \\
\hline R4 & Tangan Kanan & Kanan \\
\hline R5 & Tangan Kanan & Kanan \\
\hline R6 & Tangan Kanan & Kanan \\
\hline R7 & Tangan Kanan & Kanan \\
\hline R8 & Tangan Kanan & Kiri \\
\hline R9 & Tangan Kiri & Kanan \\
\hline R10 & Tangan Kiri & Kanan \\
\hline R11 & Tangan Kiri & Kiri \\
\hline R12 & Tangan Kiri & Kanan \\
\hline R13 & Tangan Kiri & Kanan \\
\hline R14 & Tangan Kiri & Kanan \\
\hline R15 & Tangan Kiri & Kanan \\
\hline R16 & Tangan Kiri & Kiri \\
\hline
\end{tabular}

Dari Tabel 4 kemudian dihitung persentase pilihan sidebar. $78 \%$ responden lebih menyukai sidebar berada di sebelah kanan. $22 \%$ responden menyukai sidebar berada disebelah kiri. Hasil wawancara dan hasil pengujian usability menggunakan SUS memiliki kesamaan bahwa sidebar kanan merupakan pilihan terbaik untuk diterapkan pada personal website. 
Wawancara tidak hanya menanyakan mengenai pilihan dalam posisi sidebar, juga ditanyakan alasan memilih posisi sidebar tersebut. Dari semua responden baik yang memiliki dominan tangan kanan dan tangan kiri, rata-rata responden memberikan alasan memilih sidebar kanan adalah karena sudah terbiasa mengakses website yang memiliki sidebar disebelah kanan.

Hasil dari penelitian ini merekomendasikan posisi sidebar pada desain UI personal website terletak disebelah kanan. Penerapan posisi sidebar pada sebelah kanan bisa juga diterapkan selain personal website. Karena mayoritas pengguna lebih menyukai website dengan sidebar sebelah kanan berdasarkan kebiasaan.

Dari hasil penelitian juga mendapatkan pemahaman baru bahwa untuk memudahkan dalam perancangan desain UI website, faktor kebiasaan perlu menjadi bahan pertimbangan. Hal ini bertujuan untuk mendapatkan tingkat usability yang bagus. Salah satu cara paling mudah dalam merancangan UI adalah mengikuti desaindesain UI yang sudah poluler atau dalam penelitian [9] disebut dengan mengadopsi Common Element Sets (CES).

\section{KESIMPULAN}

Pengujian usability pada penelitian ini adalah membandingkan antara penerapan sidebar kanan dan kiri pada personal website. Skor usability Personal website dengan sidebar sebelah kanan lebih tinggi dibandingkan dengan sidebar sebelah kiri, masing-masing mendapatkan skor 80 dan 59 dengan menggunakan SUS. Secara sederhana dapat disimpulkan bahwa sidebar kanan merupakan pilihan terbaik untuk diterapkan pada personal website. Hal ini juga didukung dari hasil wawancara, responden lebih memilih sidebar pada personal website berada disebelah kanan. Berdasarkan faktor usabiliy, posisi sidebar pada personal website direkomendasikan terletak disebelah kanan.

\section{DAFTAR PUSTAKA}

[1] M. Khedher, "Personal branding phenomenon," International journal of information, business and management, vol. 6, no. 2, p. 29, 2014.

[2] N. Nwiabu, I. Allison, P. Holt, P. Lowit, and B. Oyeneyin, "User interface design for situation-aware decision support systems," in 2012 IEEE International Multi-Disciplinary Conference on Cognitive Methods in Situation Awareness and Decision Support. IEEE, 2012, pp. 332-339.

[3] J. Veen, "The art and science of web design, $\varepsilon \kappa \delta$ ó $\sigma \varepsilon \iota \varsigma$ m,” 2001.

[4] S. Kaur, K. Kaur, and P. Kaur, "Analysis of website usability evaluation methods," in 2016 3rd International Conference on Computing for Sustainable Global Development (INDIACom). IEEE, 2016, pp. 10431046.

[5] H. M. Az-zahra, W. Parwaningsuci, and M. C. Saputra, "Usability evaluation of user interface in badan narkotika nasional east java province website," in 2018 International Conference on Sustainable Information Engineering and Technology (SIET). IEEE, 2018, pp. 262-265.

[6] T. S. Tullis and J. N. Stetson, "A comparison of questionnaires for assessing website usability," in Usability professional association conference, vol. 1. Minneapolis, USA, 2004.

[7] A. Bangor, P. Kortum, and J. Miller, "Determining what individual sus scores mean: Adding an adjective rating scale," Journal of usability studies, vol. 4, no. 3, pp. 114-123, 2009.

[8] Z. Sharfina and H. B. Santoso, "An indonesian adaptation of the system usability scale (sus)," in 2016 International Conference on Advanced Computer Science and Information Systems (ICACSIS). IEEE, 2016, pp. 145-148.

[9] E. Susilo, F. D. Wijaya, and R. Hartanto, "Perancangan dan evaluasi user interface aplikasi smart grid berbasis mobile application,” Jurnal Nasional Teknik Elektro dan Teknologi Informasi (JNTETI), vol. 7, no. 2, pp. 150-157, 2018. 


\section{BIOGRAFI PENULIS}

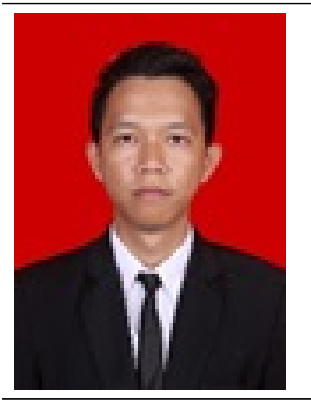

Edi Susilo obtained Bachelor Degree in Education of Informatics Engineering from Yogyakarta State University in 2014, obtained Master Degree in Informatics Engineering from University Of AMIKOM Yogyakarta in 2017, and obtained Master Degree in Electrical Engineering from Universitas Gadjah Mada in 2018. He has been a Lecturer with the Program In Informatics Engineering, University of Riau, since 2019. His current research interests include human computer interaction, usability, user interface, and user experience.

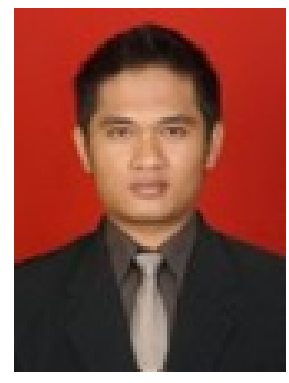

Salhazan Nasution obtained Bachelor Degree in Informatics Engineering from Islamic University of Indonesia in 2008, and obtained Master Degree in Management Information System from The National University of Malaysia in 2014. He has been a Lecturer with the Program In Informatics Engineering, University of Riau, since 2015. His current research interests include Information System, Software Engineering, Mobile Application, IoT.

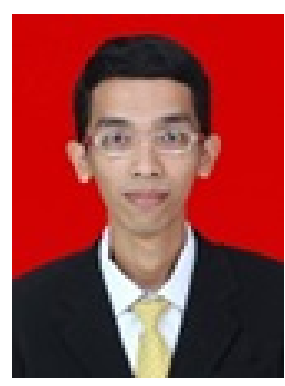

Rahmat Rizal Andhi obtained Bachelor Degree in Informatics Engineering from Pasundan University in 2013, and obtained Master Degree in Electrical Engineering from Bandung Institute of Technology in 2016. He has been a Lecturer with the Program In Informatics Engineering, University of Riau, since 2016. His current research interests Mobile Development, Animation, Mixed Reality, and Game. 